\title{
Trichilemmal Cyst at Wrist: A Rare Site of Occurence
}

\author{
Ruchi Sinha ${ }^{1}$, Iffat Jamal ${ }^{1 *}$, Shashikant Kumar ${ }^{1}$ and Purushottam Kumar ${ }^{2}$ \\ ${ }^{1}$ Department Of Pathology , All India Institute Of Medical Sciences, Patna, India \\ ${ }^{2}$ Department Of Surgery, All India Institute Of Medical Sciences, Patna, India
}

\section{Dear Sir,}

A 30 year old lady presented with a painless swelling on the dorsum of right wrist for one year which was gradually increasing in size .There was no associated pain or difficulty in movement of the wrist joint. Clinical examination revealed a well-defined, $3 \times 2 \mathrm{~cm}$, firm,nontender subcutaneous lesion over the dorsum of right wrist which was free from underlying structures (Figure 1).

There was no impairment of function and sensation of the right wrist,hand and digits.Fine needle aspiration of the lesion was performed and cytological diagnosis of epidermal inclusion cyst was made .

Considering the progressive increase in size, the lesion was surgically excised and sent for histopathological examination. Grossly a globular, smooth, well encapsulated and pearly white mass of size $2 \times 1.5 \times 1 \mathrm{~cm}$ was received, cut section of which revealed a solid and homogenous mass with lamellated appearance (Figure 2) . Histopatholgical examination confirmed it to be a trichilemmal cyst (Figure 3).

Trichilemmal cyst also called pilar cyst,isthmus-catagen cyst or wen are commonly present in areas with dense hair follicle concentrations.About $90 \%$ of trichilemmal cysts occur in scalp. Other sites are face,neck, trunk, buttock and elbow ${ }^{[1]} \mathrm{A}$ trichilemmal cyst over the wrist is quite rare and very few cases have been reported so far in literature. This makes our case worth reporting.

Histopathology of trichilemmal cyst shows epithelial cells possessing no clear visible intercellular bridges and is characterized by sudden keratinisation without the formation of a granular layer with an uneven interphase between the keratinized and the nonkeratinised cells. ${ }^{[2]}$ The keratin in the cyst is non- lamellated with retention of some nuclei. Focal calcification and foreign body giant cell reaction is also present. ${ }^{[3]}$ Trichilemmal cysts are almost always benign, although malignant transformation can be seen in $2 \%$ cases.A spectrum of transformation from benign pilar cyst to a proliferating tumor to malignant proliferating trichilemmal tumor can be encountered.$^{[4]}$
The possible differential diagnoses that should be considered at this location are epidermal inclusion cysts,lipoma,ganglion and hibernoma. ${ }^{[5]}$ Histopathology is needed for a definitive diagnosis. Knowledge about morphology of different cystic lesion and its behavior is essential to come to a correct diagnosis.Unusual presentation of benign cystic lesion can lead to clinical misdiagnosis. This case not only highlights the unusual location of trichilemmal cyst but also the importance of doing histopathological examination to avoid misdiagnosis. Treatment consists of surgical excision.

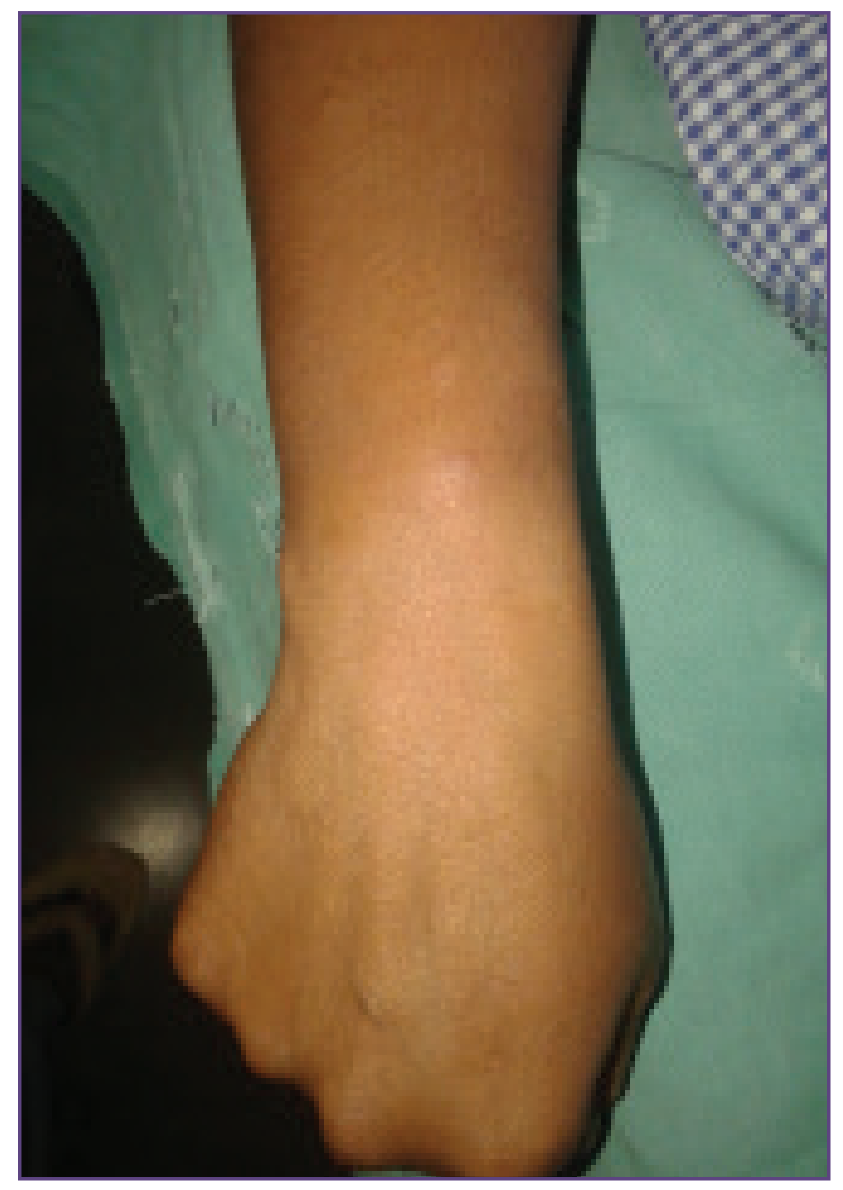

Fig. 1: Clinical photograph of the patient showing a swelling on the dorsum of right wrist. 

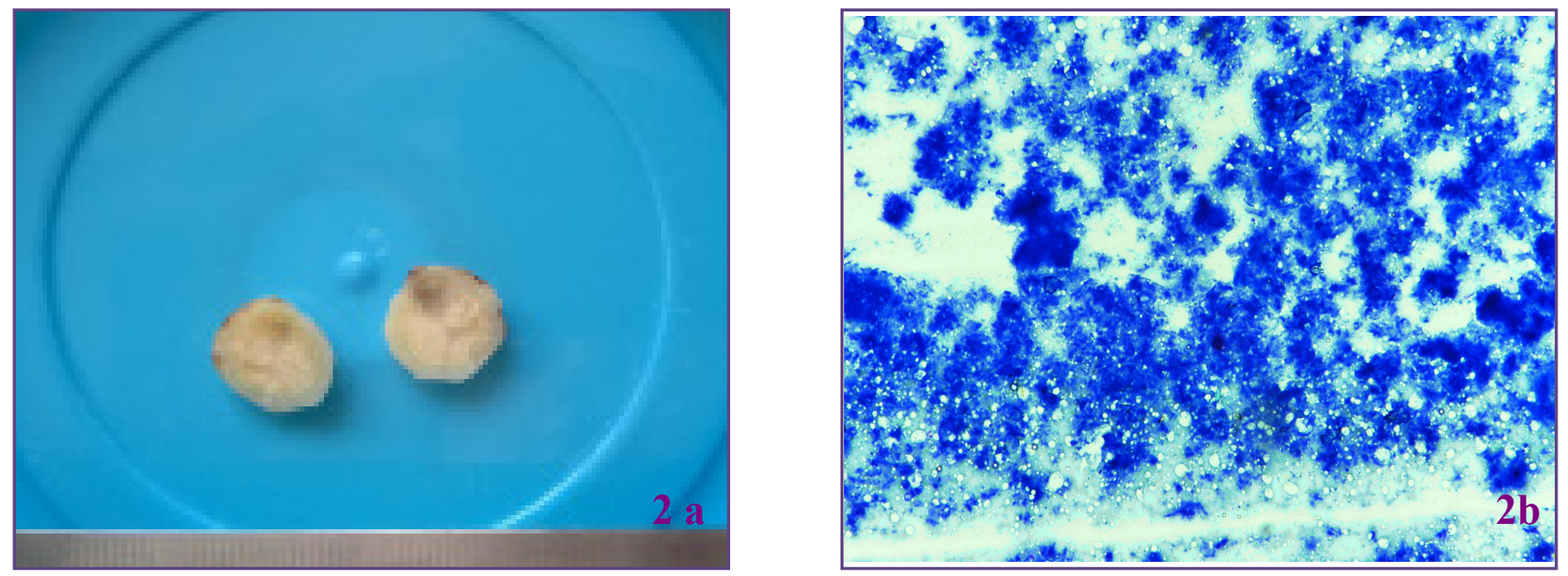

Fig. 2: a) Gross image of the resected specimen from wrist showing a globular and pearly white lamellated mass. b) FNA aspirate of the lesion showing anucleate squames in keratinous background. ( MGG;400X)
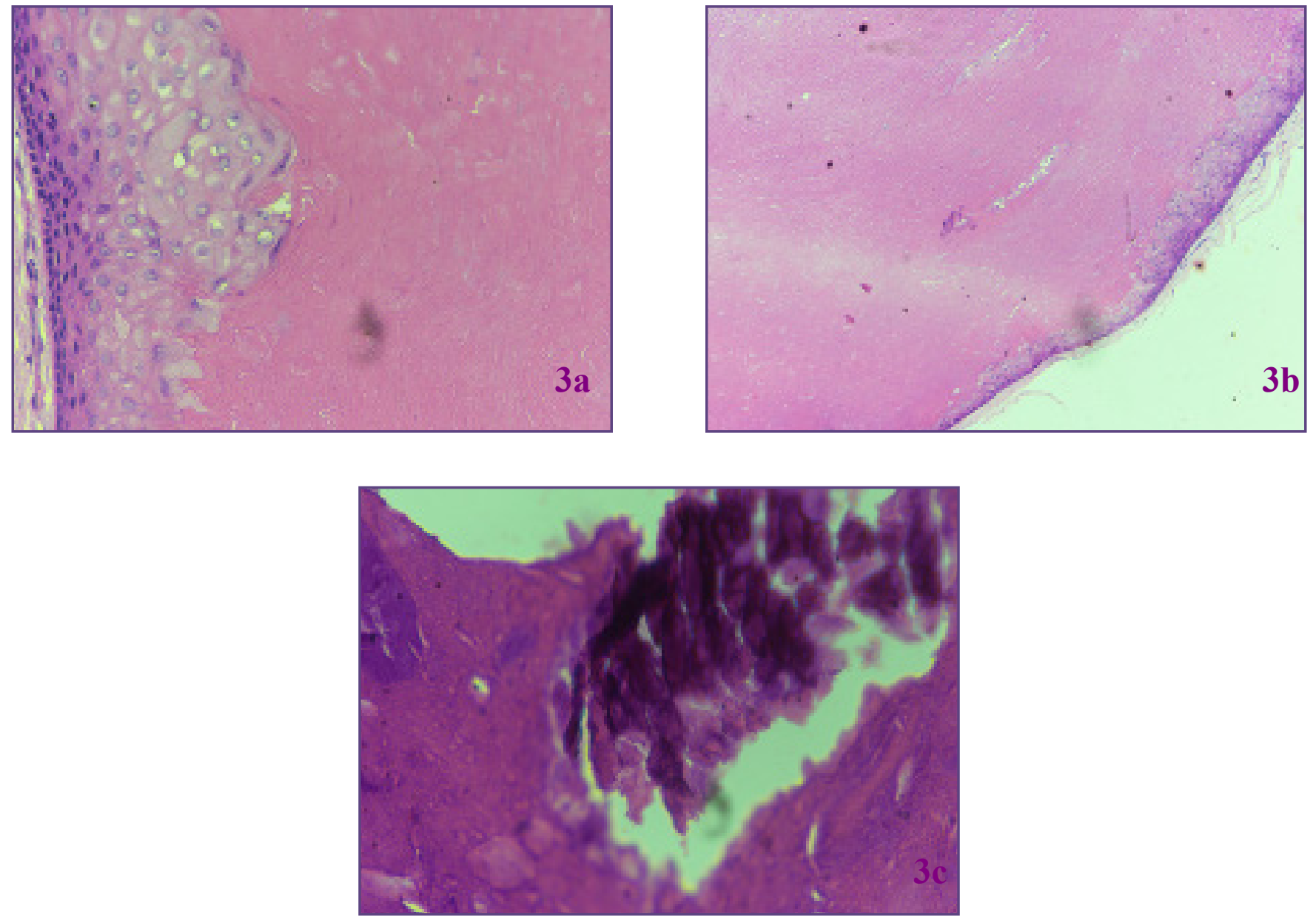

Fig. 3: a) Microphotograph showing absence of granular layer with abrupt interphase between keratinized and nonkeratinised cells.( H \& E;400X). b): microphotograph showing a cyst lined with squmaous epithelium undergoing sudden keratinization ( H\&E;100 X) and c): focal calcification.( H \& E ; 400X). 


\section{Reference}

1. Mcgavran MH, Bennington B. Keratinous cysts of the skin.Identification and differentiation of Pilar cysts from Epidermal cysts. Arch Dermatol 1996;94:499-508.

2. Adya KA, Inamdar AC. Multiple firm swellings over the scalp. Int.J Trichology 2012;4:98-9.

3. Ikegami T, Kameyama M, Orikasa H, Yamazaki K. Trichilemmal cyst in the pulp of index finger.A case report. Hand Surg 2003;8:253-5.
4. Sadath HN, Ramachandra S, Kumar MA, Harithka K. Multicentric calcified trichilemmal cysts with alopecia universalis affecting siblings.Indian Journal Deramtol Venereol Leprol 2013;79:88-91.

5. Anolik R, Firoz B, Walters RF, Meehan SA, Tsou HC, Whitlow $\mathrm{M}$, et al.Proliferating trichilemmal cyst with focal calcification.Dematol Online J 2008;14-25.

*Corresponding author:

Dr. Iffat Jamal, Flat No-D/2, Phase-1, Sapna Apartment, Nayatola, Patna-800004, Bihar, India

Phone: +91 - 09835498843

Email: Iffatjamal111@Gmail.Com

Date of Submission : 18.11.2016

Date of Acceptance : 12.01.2017

Financial or other Competing Interests: None.
Date of Publication : 31.03.2017 